\title{
EFEKTIVITAS PEMBELAJARAN MATEMATIKA REALISTIK DI TINJAU DARI KEMAMPUAN PEMECAHAN MASALAH MATEMATIKA SISWA SMP
}

\author{
Advensius Fitalis Mauk ${ }^{1}$, Stanislaus Amsikan², Yohanis Ndapa Deda ${ }^{3 *}$ \\ 1,2Prodi Pendidikan Matematika Fakultas Ilmu Pendidikan, Universitas Timor \\ Jalan Km 09 Kelurahan Sasi, Kefamenanu, Indonesia \\ e-mail: ${ }^{3}$ yndapadeda@gmail.com;
}

Submitted: July 12,2021

Revised: August 8, 2021

Accepted: August 21, 2021

corresponding author*

\begin{abstract}
Abstrak
Penelitian ini bertujuan untuk mengetahui keefektifan Pembelajaran Matematika Realistik (PMR) ditinjau dari kemampuan pemecahan masalah siswa kelas VII SMP. Jenis penelitian yang digunakan adalah penelitian eksperimen semu (quasi eksperiment). Teknik pengumpulan data dengan menggunakan metode observasi dan metode tes. Data hasil penelitian dianalisis menggunakan uji $Z$ kolmogorov-Smirnov dengan bantuan SPSS. Hasil penelitian menunjukan bahwa ada keefektifan pendekatan pembelajaran matematika realistik ditinjau dari kemampuan pemecahan masalah matematika siswa SMP. Berdasarkan tabel output "Group Statistics" diketahui jumlah data kemampuan pemecahan masalah kelas eksperimen adalah 15 siswa dalam kelas control dan 15 siswa yang dilakukan secara konvensional. Nilai rata-rata kemampuan pemecahan masalah matematika siswa untuk kelompok eksperimen adalah 78,27 dan kelompok kontrol adalah 70,07. Penafsiran tabel output Independent Samples Test berpedoman pada nilai yang terdapat dalam tabel "Equal variances assusmed". Berdasarkan tabel output "Independent Samples Test" pada bagian "Equal variances assumed" diketahui nilai Sig. (2-tailed) sebesar 0,01<0,05, maka sebagaimana dasar pengambilan keputusan dalam uji independent sample t test dapat disimpulkan bahwa Ho ditolak dan Ha diterima. Dengan demikian dapat disimpulkan bahwa pendekatan Pembelajaran Matematika Realistik (PMR) lebih efektif ditinjau dari kemampuan pemecahan masalah matematika siswa SMP.
\end{abstract}

Kata Kunci: pembelajaran matematika realistik, kemampuan pemecahan masalah matematika, $z$ kolmogorov-smirnov

\section{THE EFFECTVENESS OF REALISTIC MATHEMATICS LEARNING IN TERMS OF THE MATHEMATICAL PROBLEM SOLVING ABILITIES OF JUNIOR HIGH SHCOOL STUDENTS}

\begin{abstract}
This study aims to determine the effectiveness of Realistic Mathematics Learning in terms of the mathematical problem-solving abilities of seventh-grade junior high school students. The type of research used is quasi-experimental research. Data collection techniques using documentation methods test methods. Research data and analysis using the Kolmogorov-Smirnov Z test with the help os SPSS. The results showed that there was the effectiveness of Realistic Mathematics problem-solving abilities of grade VII Students of SMP Santu Ignasius Fahiluka-Bolan. Based on the output table "Group Statistic", it is known that the number of data on the problem-solving ability, the experimental class is 15 students and the control class is 15 students. The Average math problem-solving skills of the students (mean) in the experimental group was 78,27 end the control group was 70,07. The interpretation of the output table is independent of the test samples guided by the values contained in the "Equal Variances Assumed" table. Based on the output table "Independent Samples Test" in the "Equal Variances Assumed" section, it is known the sig. (2-tailed) value is $0,01<0,05$ so as the decision making Ho is rejected and Ha is accepted. Thus it can be concluded that the Realistic Mathematics Learning approach is more effective in terms of the mathematics problems for junior high school students.
\end{abstract}

Keywords: realistic mathematics learnin, math problem solving skills, kolmogorov-smirnov z

Copyright $\odot$ Authors. This is an open access article distributed under the Attribution-NonCommercialShareAlike 4.0 International (CC BY-NC-SA 4.0), which permits unrestricted use, distribution, and reproduction in any medium, provided the original work is properly cited. 


\section{Pendahuluan}

Pendidikan matematika realistik adalah sebuah pendekatan pembelajaran matematika yang dikembangkan Freudenthal di Belanda. Gravemeijer (1994) menjelaskan bahwa yang dapat digolongkan sebagai aktivitas pembelajaran seperti, aktivitas mengidentifikasi masalah, dimana siswa dapat memahami manfaat pembelajaran matematika kemudian melihat problema dalam kehidupan sehari-hari. Aktivitas mengorganisasi pokok persoalan, dari permasalahan yang dapat ditemui dalam kehidupan nyata, kemudian dari problema tersebut disatukan untuk mendapatkan pokok permasalahan. Pemecahan masalah, dari pokok permasalahan yang dapat ditemukan dalam dunia nyata kemudian problema-problema tersebut dapat diselesaikan/ memecahkan dengan ide atau rumus yang dapat diterima dari guru atau buku. Matematika realistik yang dimaksudkan dalam hal ini adalah matematika sekolah yang dilaksanakan dengan menempatkan realitas dan pengalaman siswa sebagai titik awal pembelajaran. Masalahmasalah realistik digunakan sebagai sumber munculnya konsep-konsep matematika atau pengetahuan matematika formal.

Proses pembelajaran di kelas selama ini masih didominasi guru (Fauziah dan Zulfiati, 2020). Selain itu, Pembelajaran cenderung prosedur yang hanya menekankan pada kemampuan siswa menghafal cara menjawab soal yang diberikan guru (Fitria, 2017).

$$
\text { Ifa-muyiwa dan Ajilogba }
$$

mengungkapkan peserta didik kesulitan dalam mempertahankan dan mengingat materi-materi atau hal-hal yang tidak bermakna dan tidak bermanfaat dalam kehidupan sehari-hari. Dalam proses pembelajaran, siswa kurang untuk mengembangkan kemampuan berfikir khususnya pada mata pelajaran matematika. Proses pembelajaran di dalam kelas diarahkan kepada kemampuan siswa untuk memahami informasi, akan tetapi siswa mamaksa diri untuk menghafal, maka siswa memaksa otak untuk mengingat dan menimbunkan berbagai pengetahuan/informasi. Akibatnya, siswa berfikir atau belajar menggunakan sitem konvensional atau siswa memperoleh sumber pembelajaran berpusat pada guru. Pada sistem pembelajaran konvensional, pembelajaran berpusat pada guru, tidak menggunakan konteks yang mudah dimengerti siswa. Akibatnya siswa tidak mandiri atau berkreatif untuk belajar sendiri atau membuat masalah dari soal atau materi yang di dapatkan dari guru kemudian di pecahkan/diselesaikan sendiri. sehingga siswa didik lulus dari sekolah, mereka pintar secara teoritis akan tetapi mereka miskin aplikasi dan sikap belajar siswa menjadi rendah.

PMR merupakan salah satu pembelajaran yang dapat dipakai oleh Guru karena memudahkan siswa memahami materi dan mampu meningkatkan hasil belajar siswa dalam hal ini kemampuan pemecahan masalah, menumbuhkan aktivitas dan meningkatkan keyakinan siswa selama pembelajaran matematika khususnya pada materi. Hal ini sejalan dengan (Nila, 2009) menyatakan bahwa pendekatan Pembelajaran Matematika Realistik merupakan pendekatan dalam pembelajaran matematika yang memandang matematika sebagai suatu aktivitas manusia.

\section{Keefektifan Pembelajaran Matematika}

Keefektifan berasal dari kata efektif yang artinya mempunyai pengaruh atau akibat. Sedangkan keefektifan berarti keberhasilan terhadap suatu tindakan tertentu. Pada kegiatan pembelajaran suatu tindakan yang dimaksud adalah penggunaan pendekatan, metode atau strategi oleh guru. Dengan demikian, apabila semakin maksimal hasil yang dicapai maka semakin efektif pula suatu kegiatan pembelajaran (KBBI).

Menurut Nurtamam (2016) keefektifan pembelajaran merupakan sebagai tindakan untuk mencapai tujuan yang diperoleh setelah pelaksanaan proses pembelajaran yang akan dicapai. Dari hal tersebut bahwa hasil pembelajaran yang diperoleh dari pembelajaran dapat bermanfaat dalam kehidupan sehari-hari. Menunjukkan bahwa tercapainya tujuan pembelajaran yang telah direncanakan sehingga pembelajaran dikatakan efektif. Hal senada diungkapkan oleh Daryanto (2013) bahwa efektivitas merupakan tingkat keberhasilan dari penerapan suatu model pembelajaran, dalam hal ini diukur dalam hasil belajar siswa, apabila hasil belajar siswa meningkat maka model pembelajaran dapat dikatakan efektif. Pencapaian tujuan pembelajaran dapat berupa peningkatan pengetahuan, kecakapan, dan keterampilan. Mengetahui keefektifan suatu pembelajaran merupakan hal penting karena akan memberikan gambaran sejauh mana pembelajaran dapat mencapai tujuan. Oleh karena itu agar siswa dapat mencapai tujuan pembelajaran diperlukan kegiatan pembelajara inovatif yang memfasilitasi siswa dalam belajar sehingga siswa paham dengan konsep yang disajikan oleh guru.

Menurut O'Connel, Bamberger \& Oberdorf (2007) mengatakan bahwa pembelajara matematika adalah suatu proses pembelajaran antara guru dan siswa saling berinteraksi untuk 
mengembangkan pola pikir siswa agar siswa memiliki kemampuan untuk berpikir matematis serta memiliki pengetahuan dan keterampilan dasar matematika, dimana proses tersebut meliputi pemecahan masalah, penalaran, komunikasi, penelusuran pola atau hubungan, dan representasi.

\section{Pembelajaran Matematika Realistik}

Menurut Soedjadi (2001) PMR pada dasarnya adalah pemanfaatan realita dan lingkungan yang dipahami peserta didik untuk memperlancar proses pembelajaran matematika sehingga mencapai tujuan pendidikan matematika secara lebih baik dari sebelumnya. Pembelajaran Matematika realistik yang dimaksudkan dalam hal ini adalah matematika sekolah yang dilaksanakan dengan menempatkan realitas dan pengalaman siswa sebagai titik awal pembelajaran. Prinsip PMR yang digunakan adalah prinsip penemuan kembali melalui pemecahan masalah (Son, 2020) yang diberikan pada lembar kerja siswa.

\section{Kemampuan Pemecahan Masalah}

Kemampuan pemecahan masalah harus dimiliki oleh siswa untuk menyelesaikan soal-soal berbasis masalah. Menurut Sumarmo (2000) pemecahan masalah adalah suatu tindakan Jadi, kemampuan pemecahan masalah adalah kemampuan untuk menerapkan suatu permasalahan yang telah diperoleh sebelumnya ke dalam situasi baru yang belum dikenal.

\section{Metode Penelitian}

Jenis penelitian yang digunakan adalah penelitian eksperimen semu (quasi eksperiment). Menurut Wicaksono, Ferdianto dan Suprato (2011) untuk penelitian yang berhubungan dengan peningkatan proses pembelajaran direkomendasikan penggunaan penelitian eksperimen semu. Desain yang digunakan adalah posttest only control grup desaign. Penelitian ini sudah ilaksanakan di SMP SIF. Waktu penelitian dilaksanakan pada semester genap tahun 2020/2021. Dalam penelitian ini peneliti menggunakan dua jenis variabel yaitu variabel bebas dan variabel terikat. Variabel bebas dalam penelitian ini adalah pembelajaran dengan Pembelajaran Matematika Realistik (PMR) dan Variabel terikat dalam penelitian ini adalah kemampuan pemecahan masalah.

Populasi dalam penelitian ini adalah seluruh siswa kelas VII SMP. Sampel dalam penelitian ini diambil dengan teknik Random Sampling. Hal ini dilakukan setelah memperhatikan ciri-ciri antara lain siswa mendapat materi berdasar kurikulum yang sama, siswa diampu oleh guru yang sama, siswa yang menjadi objek penelitian duduk pada kelas yang sama dan pembagian kelas tidak ada kelas unggulan. Pada penelitian ini diambil dua kelas secara acak, yaitu kelas VII C sebagai kelas eksperimen yang dikenai Pembelajaran Matematika Realistik (PMR) dan kelas VII B sebagai kelas kontrol yang dikenai pembelajaran konvensional, dimana guru mendimnasi pembelajaran, kurang memberi kesempatan siswa untuk berpikir.

Instrumen penilaian hasil belajar adalah alat (ukur) yang digunakan dalam rangka mengumpulkan dan mengolah informasi untuk menentukan prestasi belajar peserta didik. Instrumen tes berbentuk uraian yang terdiri dari tiga soal. Tes Hasil belajar berupa soal uraian, ini dilakukan setelah perlakuan yang diberikan kepada kelas eksperimen dan kelas kontrol ketika posttest adalah sama.

Data hasil belajar siswa dikumpulkan dengan memberikan tes guna mengukur kemampuan siswa. Tes dalam penelitian ini adalah tes tertulis. Tes tertulis adalah tes yang menuntun siswa untuk memberikan jawaban secara tertulis. Selain tes, juga dilakukan observasi melalui lembar observasi yang diisi saat pembelajaran berlangsung.

\section{Hasil dan Pembahasan}

\subsection{Hasil}

Untuk menganlisa sejauh mana model pembelajaran matematika realistik efektif dalam pembelajaran matematika ditinjau dari kemampuan pemecahan masalah matematika siswa kela VII SMP Santu Ignasius FahilukaBolan, Maka dilakukan uji t satu sampel dan uji t dua sampel. Agar uji t ini dapat dilakukan maka terdahulunya perlu diuji asumsi klasik Normalitas dan Homogenitas. 
Tabel 1. Uji Normalitas Kelas Eksperimen dan Kelas Kontrol

One-Sample Kolmogorov-Smirnov Test

\begin{tabular}{llcc}
\hline & & $\begin{array}{c}\text { Kelas } \\
\text { Eksperimen }\end{array}$ & $\begin{array}{c}\text { Kelas } \\
\text { Kontrol }\end{array}$ \\
\hline $\mathrm{N}$ & 15 & 15 \\
\hline Normal & Mean & 78.27 & 70.07 \\
Parameters $^{\mathrm{a}}$ & Std. & 7.676 & 8.614 \\
& Deviation & .198 & .167 \\
\hline Most Extreme & Absolute & .157 & .148 \\
Differences & Positive & -.198 & -.167 \\
& Negative & .767 & .645 \\
\hline Kolmogorov-Smirnov Z & .599 & .799 \\
Asymp. Sig. (2-tailed) & & \\
\hline
\end{tabular}

a. Test distribution is

Normal.

Dari Uji Normalitas kelas eksperimen sebagaimana pada (Tabel 1) dengan uji Z kolmogorov-Smirnov kemampuan pemecahan masalah matematika siswa kelas eksperimen adalah sebesar 0,767 , dengan nilai signifikan sebesar 0,599>0,05, maka data kemampuan pemecahan masalah matematika siswa kelas eksperimen terdistribusi normal. Selanjutnya uji Normalitas kelas kontrol pada table 1 dengan uji Z kolmogorov-Smirnov kemampuan pemecahan masalah matematika siswa kelas kontrol adalah sebesar 0,645, dengan nilai signifikan kemampuan pemecahan masalah matematika siswa kelas kontrol sebesar $0,799>0,05$, maka data kemampuan pemecahan masalah matematika siswa kelas kontrol berdistribusi normal.

Tabel 2. Hasil Uji Homogenitas Kelas Eksperimen dan Kelas Kontrol

Test of Homogeneity of Variances

Kemampuan Hasil Belajar

\begin{tabular}{cccc}
\hline Levene Statistic & df1 & df2 & Sig. \\
\hline .775 & 1 & 28 & .386 \\
\hline
\end{tabular}

Sedangkan uji homogenitas hasil evaluasi posttes mateamtika sebagaimana pada tabel 2 menunjukan besaran nilai signifikansi 0,386 > 0,05 maka dapat disimpulkan bahwa varian dari kemampuan pemecahan masalah matematika kelas eksperimen dengan kelas kontrol adalah sama/homogen.
Tabel 3. Uji t Satu Sampel Kelas Eksperimen

One-Sample Test

\begin{tabular}{|c|c|c|c|c|}
\hline \multicolumn{5}{|c|}{ Test Value $=65$} \\
\hline & & $\begin{array}{l}\text { Sig. } \\
(2-\end{array}$ & Mean & $\begin{array}{l}95 \% \text { Confidence } \\
\text { Interval of the } \\
\text { Difference }\end{array}$ \\
\hline $\mathrm{T}$ & Df & tailed) & Difference & Lower \\
\hline
\end{tabular}

Kemamp

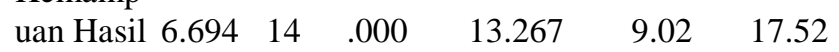

Belajar

Setelah diketahui hasil analisia tes kemampuan pemechan masalah matematika siswa yeng berdistribusi normal dan homogen maka selanjutnya dilakukan uji $t$ satu sampel. Berdasarkan hasil tes kemampuan pemecahan masalah matematika siswa dengan nilai rata-rata kemampuan pemecahan masalah matematika siswa kelas eksperimen sebesar 78,27 berdasarkan Nilai KKM 65 maka 78,27> 65, sehingga pembelajaran dengan PMR efektif ditinjau dari indeks keefektifan kemampuan pemecahan masalah matematika siswa. Apabila dilakukan uji t sampel pada (Tabel 3), diketahui nilai sig.(2-tailed) sebesar $0,000<0,05$ maka sesuai dengan dasar pengambilan keputusan Ha diterima. Maka dapat ditarik kesimpulan bahwa implementasi PMR pada pembelajaran matematika kelas VII SMP Santu Ignasius Fahiluk-Bolan tahun ajaran 2020/2021 efektif berdasarkan indeks keefektifan di tinjau dari kemampuan pemecahan masalah matematika siswa dan memiliki nilai rata-rata lebih besar dari 65.

Tabel 4. Uji t Satu Sampel Kelas Kontrol

One-Sample Test

\begin{tabular}{lccccccc}
\hline & \multicolumn{4}{c}{ Test Value $=65$} \\
\hline & & \multicolumn{4}{c}{$\begin{array}{c}\text { Sig. } \\
(2-\end{array}$} & $\begin{array}{c}\text { Mean } \\
\text { tailed }\end{array}$ & $\begin{array}{c}\text { Differe } \\
\text { Confidence } \\
\text { Interval of the } \\
\text { Difference }\end{array}$ \\
& T & Df & ) & nce & Lower & Upper \\
\hline $\begin{array}{l}\text { Kemampu } \\
\text { an Hasil } \\
\text { Belajar }\end{array}$ & 2.278 & 14 & .039 & 5.067 & .30 & 9.84 \\
\hline
\end{tabular}

Berdasarkan hasil tes kemampuan pemecahan masalah dengan nilai rata-rata kemampuan pemecahan masalah matematika siswa kelas kontrol sebesar 70,07, berdasarkan KKM 65 maka 70,07 > 65, sehingga pembelajaran dengan pendekatan Konvensional efektif ditinjau dari indeks keefektifan kemampuan pemecahan masalah matematika siswa. Apabila dilakukan uji $\mathrm{t}$ satu sampel pada (Tabel 4), diketahui nilai sig.(2tailed) sebesar $0,039<0,05$ maka sesuai dengan 
dasar pengambilan keputusan Ha diterima. Maka dapat ditarik kesimpulan bahwa implementasi Konvensional pada pembelajaran matematika siswa kelas VII SMP Santu Ignasius Fahiluk Bolan tahun ajaran 2020/2021 efektif berdasarkan indeks keefektifan di tinjau dari kemampuan pemecahan masalah matematika siswa dan memiliki nilai ratarata lebih besar dari 65 .

Tabel 5. Hasil Uji T Dua Sampel Kelas Eksperimen dan Kelas Kontrol

Independent Samples Test

Levene's Test

for Equality

of Variances

t-test for Equality of Means

\begin{tabular}{|c|c|c|c|c|c|c|c|c|c|c|}
\hline & & \multirow[b]{2}{*}{ F } & \multirow[b]{2}{*}{ Sig. } & \multirow[b]{2}{*}{$\mathrm{T}$} & \multirow[b]{2}{*}{ Df } & \multirow{2}{*}{$\begin{array}{l}\text { Sig. (2- } \\
\text { tailed) }\end{array}$} & \multirow{2}{*}{$\begin{array}{c}\text { Mean } \\
\text { Difference }\end{array}$} & \multirow{2}{*}{$\begin{array}{l}\text { Std. Error } \\
\text { Difference }\end{array}$} & \multicolumn{2}{|c|}{$\begin{array}{l}95 \% \text { Confidence } \\
\text { Interval of the } \\
\text { Difference }\end{array}$} \\
\hline & & & & & & & & & Lower & Upper \\
\hline \multirow[t]{2}{*}{$\begin{array}{l}\text { Kemampuan } \\
\text { Pemecahan } \\
\text { Masalah }\end{array}$} & $\begin{array}{l}\text { Equal } \\
\text { variances } \\
\text { assumed }\end{array}$ & .960 & .336 & 2.752 & 28 & .010 & 8.200 & 2.979 & 2.097 & 14.303 \\
\hline & $\begin{array}{l}\text { Equal } \\
\text { variances } \\
\text { not } \\
\text { assumed }\end{array}$ & & & 2.752 & 27.636 & .010 & 8.200 & 2.979 & 2.094 & 14.306 \\
\hline
\end{tabular}

Pada uji t dua sampel sebagaimana pada (Tabel 5) berdasarkan tabel output "Group Statistics" diketahui jumlah data kemampuan pemecahan masalah kelas eksperimen adalah 15 siswa dalam kelas kontrol adalah 15 siswa. Nilai rata-rata kemampuan pemecahan masalah matematika siswa (mean) kelas eksperimen adalah 78,27 dan kelas kontrol adalah 70,07. Penafsiran tabel output Independent Samples Test berpedoman pada nilai yang terdapat dalam tabel "Equal variances assusmed". Berdasarkan tabel output "Independent Samples Test" pada bagian "Equal variances assumed" diketahui nilai Sig. (2tailed) sebesar $0,010<0,05$, maka sebagaimana dasar pengambilan keputusan dalam uji independent sample $t$ test dapat disimpulkan bahwa Ho ditolak dan Ha diterima. Dengan demikian dapat disimpulkan kedua pendekatan pembelajaran yaitu pembelajaran dengan menggunakan pendekatan Pembelajaran Matematika Realistik (PMR) dan pendekatan Konvensional dapat disimpulkan bahwa pendekatan Pembelajaran Matematika Realistik (PMR) lebih efektif ditinjau dari kemamuan pemecahan masalah matematika siswa kelas VII SMP SIF Tahun Pelajaran 2020/2021.

Hasil penelitian menunjukkan bahwa pembelajaran matematika dengan model pembelajaran matematika realistik dapat membuat siswa menjadi lebih semangat karna dalam pembelajaran siswa dan siswa saling berinteraksi dengan kelompoknya dan siswa dengan sendirinya tenang tanpa harus diatur. Hal ini terjadi karena pembelajaran matematika menggunakan masalah kontekstual dalam pemecahan masalah, selain itu siswa dapat pengalaman menyelesaiakan masalah nyata dalam kehidupan sehari-hari. Peneliti pada awal mengikuti proses pembelajaran sampai akhir pembelajaran dibandingkan dengan pembelajaran matematika menggunakan metode konvensional, karena pada proses pembelajaran dengan pendekatan pembelajaran matematika realitik, siswa menjadi lebih aktif dalam belajar dan bekerja sama dalam kelompok. Dengan menggunakan Pembelajaran Matematika Realistik (PMR) dalam proses kegiatan belajar mengajar mampu membuat siswa cepat paham. Pada awal pembelajaran terlebih dahulu guru menjelaskan tujuan dan pendekatan pembelajaran dengan menjelaskan tentang logistik atau kelengkapan yang dibutuhkan serta memberikan motivasi kepada siswa. Kemudian guru memberikan LKS untuk dikerjakan siswa secara berkelompok, dalam kelompok terdapat 5 orang siswa. Didalam LKS tersebut terdapat permasalahan kontekstual yang terjadi pada kehidupan sehari-hari sehingga membuat siswa merasa bahwa matematika benar ada dan hadir dalam kehidupan.

Kemudian siswa mendiskusikan pemecahan masalah matematika dengan cara mencoba untuk mengembang tingkat kemampuannya dan dilakukan secara berkelompok. Siswa kemudian mengumpulkan hasil diskusi dan dikoreksi oleh guru. Salah satu perwakilan kelompok menyampaikan hasil diskusi. Setelah itu guru mengevaluasi kembali hasil kerja siswa di depan papan tulis. 
Pada kegiatan ini terjadi interaksi yang positif antara siswa dan siswa maupun siswa dan guru diskusi tentang soal LKS yang dikerjakan sebelumnya. Siswa menjadi lebih bersemangat dan saling membantu satu sama lain dalam menyelesaikan soal didalam kelompok. Apabila ada kesalahan dalam pembahasan soal didalam kelompok, siswa langsung menanyakan solusinya pada guru dengan tidak ragu-ragu dan tidak malu. Siswa dan guru sama-sama mencari solusi yang tepat.

Pembelajaran matematika realistik yang membahas tentang aritmatika sosial yang berkaitan dengan kehidupan sehari-hari membuat siswa lebih bersemangat dan siswa dengan mudah memahami. Menurut Wijaya (2012), Pembelajaran Matematika Realistik adalah suatu pendekatan pembelajaran matematika yang harus mengaitkan konsep matematika dengan kehidupan nyata atau selalu menggunakan masalah sehari-hari. Sehingga dapat memudahkan siswa untuk berkontribusi dalam menyelesaikan masalah. Salah satu contoh pemecahan masalah ketika siswa dalam kelas eksperimen mengerjakan soal tentang suku bunga, siswa mampu menentukan suku bunga dari soal cerita yang dikethui modal awal dan modal akhir setelah disimpan di suatu lembaga keuangan selama 5 tahun.

Pembelajaran yang dilaksanakan pada kelas kontrol adalah pembelajaran konvensional. Menurut Sullian dan Mclntosh, (2001) menyatakan bawah metode pembelajaran konvensional adalah strategi pembelajaran berpusat pada guru atau guru lebih banyak mendominasi kegiatan pembelajaran berlangsung disekolah. Umumnya dilsksankan disekolah berlangsung dari guru ke siswa. Dalam pebelajaran konvensional terlihat proses pembelajaran lebih banyak didominasi guru dalam mentransfer ilmu, sementara siswa lebih pasif sebagai penerima informasi. Metode yang digunakan adalah ceramah dan tanya jawab. Dalam pembelajaran konvensional, guru menjelaskan materi secara urut kemudian siswa diberi kesempatan untuk mencatat. Selanjutnya guru memberikan beberapa contoh soal latihan. Kemudian guru memberikan LKS untuk dikerjakaan oleh siswa. Setelah selesai mengerjakan soal, beberapa siswa diminta untuk mengerjakan soal tersebut di papan tulis. Guru memberikan kesempatan bertanya kepada siswa mengenai hal-hal yang belum dipahami. Di akhir pembelajaran, guru menegaskan kembali tentang materi yang telah dipelajari.

Berdasarkan analisis hasil penelitian, kita ketahui bahwa kemampuan pemecahan masalah matematika siswa kelas eksperimen lebih efektif dari kemampuan pemecahan masalah matematika siswa kelas kontrol. Hal ini disebabkan karena kedua kelas ini diberi pendekatan yang berbeda. Pada kelas eksperimen dengan menggunakan pendekatan pembelajaran dengan PMR sedangkan pada kelas kontrol dengan menggunakan pembelajaran konvensional. Dalam pembelajaran menggunakan PMR siswa dibentuk kelompok sehingga dalam pembelajaran siswa dengan siswa saling berinteraksi dengan kelompok untuk memecahkan suatu masalah dalam matematika. Sesuai dengan pendapat Hidayat (2009) terjadinya proses interaksi antara siswa dalam kelompok sehingga siswa yang mampu dapat membantu siswa yang kurang mampu dengan tujuan untuk meningkatkan kemampuan berpikir dan belajar. Hasil penelitian ini telah sejalan dengan hasil penelitian yang mengatakan bahwa dengan PMR, aktifitas siswa dalam pembelajaran efektif dan hasil belajar meningkat (Uskono, Djong dan Leton; Noor dan Muslimah, 2019).

\section{Kesimpulan}

Berdasarkan hasil pengujian, pengolahan data dan analisis data kedua pendekatan pembelajaran yaitu pembelajaran dengan menggunakan pendekatan Pembelajaran Matematika Realistik (PMR) dan pendekatan Konvensional dapat disimpulkan bahwa pendekatan PMR lebih efektif ditinjau dari kemampuan pemecahan masalah matematika siswa SMP.

\section{Daftar Pustaka}

Daryanto, D. (2013). Media Pembelajaran Peranannya Sangat Penting Dalam Mencapai Tujuan Pembelajaran. Yogyakarta: Gava Media.

Fauziah, D.S.M, \& Zulfiati, H.M. (2020) peran guru dalam mengembangkan sikap sosial peserta didik pada pembelajaran tematik bermuatan ilmu pengetahuan sosial kelas iv sdn pendemsari sleman. Trihayu: Jurnal Pendidikan Ke-SD-an, Vol. 6, Nomor 2, Januari 2020, hlm.850-855.

Fitria, Y. (2017). Efektivitas capaian kompetensi belajar siswa dalam pembelajaran sains di sekolah dasar. JIPPSD, Vol. 1 Nomor 2, 34-42.

Gravemeijer. (1994). Developing Realistic Mathematics Education. Utrecht: Freudenthal Institute. http://repository.upi.edu/operator/upload/d_mat 0604957_chapter2.pdf

Hidayat, E. (2009). Peningkatan Kemampuan Komunikasi Matematik dan Kemandirian Belajar Siswa Sekolah Menengah Pertama dengan Menggunaka Pendekatan Matematika 
Realistik. Tesis Sekolah Pasca sarjana Universitas Pendidikan Indonesia. Bandung.

Ifamuyiwa, A. S dan Ajilogba, S. I. (2012). A Problem Solving Model as A Strategy for Improving Secondary School Students' Achievement and Retention in Further Mathematics. ARPN Journal of Science and Technology, 2(2): 122130.

Nila, K. (2009). "Peningkatan kemampuan pemecahan masalah matematis siswa smp melalui pendekatan pendidikan matematika realistik." In Seminar Nasional Matematika dan Pendidikan Matematika 2009, 484-93. Universitas Negeri Yogyakarta: Jurusan Pendidikan Matematika FMIPA UNY. http://eprints.uny.ac.id/7049/.

Noor, N. A., \& Muslimah, M. (2020). IMPLEMENTASI PEMBELAJARAN MATEMATIKA REALISTIK DALAM MENINGKATKAN HASIL BELAJAR OPERASI PENGURANGAN BILANGAN CACAH. RANGE: Jurnal Pendidikan Matematika, 1(2), 93-100.

Nurtamam, M. E. (2016). Keefektifan Pembelajaran Langsung Dengan Laboratorium Mini Untuk Materi Jajargenjang Di Kelas IV SDN Bancaran 1. Widyagogik, Vol. 3 No. 2 Januari-Juni 2016

O'Connel S., Bamberger J. H. dan Oberdorf C. (2007). Introduction to Connection, Grade 3-5. The Math Process Standars Series. Portsmouth: Heinemann.

Uskono, I. V., Djong, K. D., \& Leton, S. I. (2020). Penerapan Model Pembelajaran Matematika
Realistik Pada Pokok Bahasan Bilangan Bulat. Range: Jurnal Pendidikan Matematika, 1(2), 138-144.

Soedjadi, R. (2001). Pemanfaatan Realitas dan Lingkungan dalam Pembelajaran Matematika. Makalah disajikan pada Seminar Nasional Realistic Mathematics Education (RME) di Jurusan FMIPA UNESA tanggal 24 Februari 2001.

Son, A. L. (2020). Meningkatkan Kemampuan Pemecahan Masalah dan Koneksi Matematis serta Kemandirian Belajar Siswa SMP Melalui Pembelajaran Model CORE dengan Realistic Mathematics Education (Suatu Penelitian Ditinjau dari Gaya Kognitif) (Doctoral dissertation, Universitas Pendidikan Indonesia).

Sullivan, R. L. dan Mclntosh, N. (2001). Delivering Efectice Lectures. Baltimore Maryland: JHIEGO Coorporation.

Sumarmo, U. (1994). Suatu Alternatif Pengajaran untuk Meningkatkan Kemampuan Pemecahan Masalah pada Guru dan Siswa SMA di Kodya Bandung. Laporan Penelitian. IKIP Bandung: Tidak Dipublikasikan.

Wicaksono. S., Ferdianto. J., dan Suprato. E. (2011). Desain Penelitian menggunakan Quasi Experiment. Malang: Unver sitas Negeri Malang

Wijaya. A. (2012). Pendidikan Matematika Realistik, Suatu Alternatif Pendekatan Pembelajaran Matematika. Yogyakarta: Graha Ilmu 